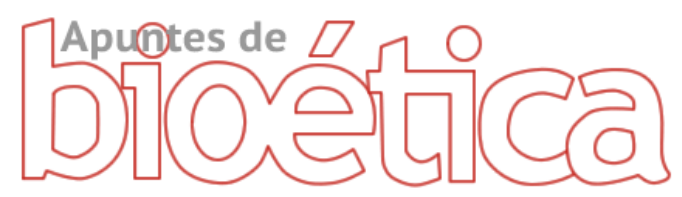

https://doi.org/10.35383/apuntes.v2i1.237

\title{
Sobre los nuevos Derechos Humanos
}

(A raíz del supuesto de fecundación artificial de mujer sola)

\author{
María Cruz Díaz de Terán Velasco ${ }^{1}$
}

\section{INFORMACIÓN DEL ARTÍCULO RESUMEN}

Historia del artículo:

Recibido el 18 de marzo de 2019

Aceptado el 08 de julio de 2019

\section{Palabras claves:}

Derechos humanos

Reproducción asistida

Maternidad en solitario
El artículoº siguiendo el pensamiento de J. Ballesteros, lleva a cabo una reflexión sobre el amparo y la promoción de la maternidad en solitario por fecundación artificial que regula la normativa española. La reflexión se hace desde un aspecto clave de la antropología jurídica, como es la alteridad, y el lugar que ocupa en la tarea de encontrar el sentido del Derecho.

\section{ABOUT THE NEW HUMAN RIGHTS (Following the assumption of artificial fertilization of women alone)}

\section{ABSTRACT}

\section{Keywords:}

Human Rights

Assisted Human Reproduction

Single Motherhood
The article, following the thought of J. Ballesteros, carries out a reflection on the protection and the promotion of single maternity by assisted human reproduction, regulated by the Spanish Law. The reflection is made from a key aspect of legal anthropology, such as otherness, and the place it occupies in the task of finding the real meaning of Law.

\footnotetext{
${ }^{1}$ Doctora en Derecho (2002) por la Universidad de Navarra. Profesora Titular acreditada de Filosofía del Derecho. Universidad de Navarra. Navarra, España. Email: mdiazdet@unav.es https://orcid.org/0000-0003-0729-653X

${ }^{2}$ Existe una primera versión de este artículo, publicado en J. de Lucas, E. Vidal, E. Fernández y V. Bellver, Pensar el tiempo presente. Homenaje al Profesor Jesús Ballesteros, Tirant lo Blanch, 2018, tomo II, pp. 1527-1540.
} 


\section{Introducción}

\section{Planteamiento de la cuestión}

Jesús Ballesteros, en su brillante obra Sobre el sentido del Derecho, desarrolla un apartado, dentro del capítulo dedicado a la antropología jurídica, sobre la relación entre alteridad y Derecho. Para hacerlo, parte de Heidegger y de la distinción que éste establece entre "el plano ontológico, referente a la estructura esencial del ser del hombre, en el que aparece con claridad la exigencia del otro, y el plano óntico, que corresponde al modo efectivo de realizarse tal exigencia" (Ballesteros, 1997, pág. 125). Siguiendo al autor alemán, el profesor Ballesteros afirma que el plano ontológico de la alteridad (el Mit-sein) "es algo que no puede fallar, que acompaña siempre como realidad ontológica la existencia del hombre". Cosa distinta sucede con la exigencia del cuidado con los otros (Fürsorge), que "es algo que desgraciadamente suele fallar con demasiada frecuencia" (Ballesteros, 1997, pág. 128). Y, tras analizar estas realidades en el psicoanálisis y destacar sus aportaciones para la antropología jurídica ${ }^{3}$, concluye que el contraste entre la necesidad que el hombre siente del hombre, y su ausencia en el trato concreto, justifica colmadamente la presencia del Derecho en nuestras vidas. Con sus palabras:

"Su fórmula, como ya dijimos, viene a ser la del respeto universal al otro, la vieja idea de humanitas, que reaparece con Kant: la exigencia de tratar al otro siempre como un fin, y nunca sólo como medio. Ello naturalmente supone que el Derecho no puede alcanzar el nivel de la caridad, de la donación de sí mismo y el perdón, pero impone rigurosamente al menos:

${ }^{3} \mathrm{Si}$ bien advierte el profesor de la necesidad de llevar a cabo una tarea de delimitación entre las distintas posiciones. a) La exclusión de la discriminación, en lo que se refiere a la extensión del vínculo con los otros;

b) La exclusión de la violencia en sus diversas formas, en lo que se refiere a la intensidad del mismo" (Ballesteros, 1997, pág. 128).

Estas palabras del profesor Ballesteros venían a mi memoria tras una lectura pausada de algunas de las normas que recoge la legislación española concerniente a aspectos relativos a la atención y cuidado de la salud sexual y reproductiva de la mujer. $Y$ es que, aunque es destacable, por lo que tiene de positivo, el que se haya buscado potenciar el libre desarrollo de su personalidad y su autodeterminación ${ }^{4}$, en mi opinión, algunos aspectos de la actual normativa merecen una reflexión más sosegada. La razón principal es que de las palabras del profesor se infiere $-y$ yo comparto- que la universalidad del respeto incondicionado al otro es fundamento del Derecho (Ballesteros, 1997, pág. 128), y, a mi juicio, esta afirmación presenta serias dificultades para conciliarse con algunos de los planteamientos de la normativa citada.

Entre los aspectos que merecerían un estudio sereno, a lo largo de las páginas que siguen me voy a detener en uno concreto: la facultad que el artículo 6.1 de la Ley 14/2006,

\footnotetext{
${ }^{4}$ España, desde el final de la dictadura hasta nuestros días, ha sufrido una honda y rápida transformación a muchos niveles: social, cultural, político, económico, religioso, etc. Esta transformación ha alcanzado y ha tenido su reflejo en la mujer y en el papel que ésta desempeña en la sociedad. En poco tiempo se ha pasado de una mujer "sometida" a la patria potestad de su padre o necesitada de un complemento de capacidad que le otorgaba su marido, a una mujer con plena autonomía y libertad de decisión en todos los ámbitos de su vida. Un ejemplo en el campo de la salud lo encontramos en las actuaciones de carácter preventivo que se dan en el ámbito del cáncer de mama en nuestro país. En España, los programas de detección precoz por mamografía funcionan desde el año 1992 y establecen la realización de mamografías cada dos años para todas las mujeres de edades comprendidas entre los 45 y 69 años. Bajando la edad hasta los 40 años en caso de mujeres con antecedentes familiares por esta patología. Para más información sobre el tratamiento normativo que se da al cuidado de la salud de la mujer en España, puede consultarse (San Julián \& Díaz de terán, 2013, págs. 69-88).
} 
sobre Técnicas de Reproducción Humana asistida otorga a la mujer sin pareja de acceder a la fecundación artificial con cargo a la sanidad pública ${ }^{5}$.

En mi opinión, son varias las dudas y las dificultades que esta normativa plantea para la actividad jurídica, según se expondrá en la primera parte de este trabajo. Junto a ello hay añadir una cuestión más de fondo, como es su marcado carácter individualista, tema en el que querría detenerme de un modo especial. Dos son las razones principales que me han conducido a adoptar este enfoque. La primera radica en que, según estudié en mis años de Licenciatura con el libro del profesor Ballesteros ${ }^{6}$, la alteridad es una nota esencial para el Derecho. Con otras palabras, el Derecho siempre tiene en cuenta a la persona en relación con su entorno, es decir, a la persona en sociedad. Sin embargo, en el supuesto mencionado apenas aparecen los terceros. Desde esta perspectiva, es llamativa la ausencia de cualquier referencia a los otros, tendencia que, además, se repite -a mi juicio de manera preocupante-, en muchas legislaciones nacionales en materia bioética ${ }^{7}$. En esta regulación prima la libertad de elección y configuración de la propia vida de la mujer más que las repercusiones que esas decisiones puedan tener en su salud y más que otros intereses de terceros. Ni siquiera se contempla la posible colisión de intereses. Situación que

\footnotetext{
${ }^{5}$ Posibilidad abierta por el legislador español en 1988, y regulada hoy en el artículo 6.1 de la Ley 14/2006, de Técnicas de Reproducción Humana Asistida. La normativa actual establece - a través del Real Decreto 1030/2006, de 15 de septiembre- la cartera de servicios comunes del Sistema Nacional de Salud y el procedimiento para su actualización. Según se recoge en su articulado, la sanidad pública solo financia esta prestación cuando haya un diagnóstico de esterilidad o una "indicación terapéutica". Situación que se matizó en 2013. El 22 de julio de ese año en el Consejo Interterritorial del Sistema Nacional de Salud se hizo entrega a los representantes de las distintas Comunidades Autónomas de un documento elaborado por el Grupo de Trabajo a petición del Ministerio de Sanidad proponiendo modificaciones en la cartera común básica de servicios. Entre esas modificaciones figuraba la exigencia de un diagnóstico de esterilidad para el acceso a los tratamientos de reproducción asistida.

${ }^{6}$ Me refiero a la obra BALLESTEROS, J.; Sobre el sentido del Derecho. Introducción a la Filosofía Jurídica (2 ${ }^{\mathrm{a} e d}$.), Madrid, Tecnos, 1997.

${ }^{7}$ El Tribunal Constitucional español, en Sentencia de 53/1985, de 11 de abril, señala en su fundamento jurídico quinto, que "la gestación ha generado un tertium existencialmente distinto de la madre, aunque alojado en esta".
}

podría darse, por ejemplo, en el supuesto de que el hijo quisiese investigar su origen biológico, posibilidad que la ley niega al nacido de mujer sola.

Por tanto, si como afirma Ballesteros, partimos de que, "la valoración positiva del Derecho aparece sólo donde se reconoce la paridad ontológica entre el yo y el otro, y no donde se potencia unilateralmente el yo" (Ballesteros, 1997, pág. 129), y dado que la actividad que se comenta se caracteriza porque su principio rector es exclusivamente el libre juego de la subjetividad, podemos afirmar que, desde esta perspectiva, presenta un difícil encaje en el Derecho.

La segunda razón, en consonancia con la anterior, es que el artículo 6.1 apela al deseo de ser madre, es decir, se apoya en la dimensión sentimental de la persona, no en su dimensión, relacional, objetiva y universal. Pero el Derecho, como ya vieron los romanos, y repite lo mejor del pensamiento jurídico contemporáneo, no está al servicio de los sentimientos, que, por definición, son mudables, sino que está a disposición de la seriedad y la estabilidad de la voluntad (Ballesteros, 1997, pág. 130). El Derecho desempeña el papel de estructura fundamental de la coexistencia. Por eso, en sus dimensiones más profundas, es duración, continuación, porque viene a establecer la fidelidad, el compromiso de las acciones humana que son relevantes para otros. Por tanto, una visión instantaneísta del Derecho, centrado en la satisfacción inmediata de deseos individuales, conduce a contemplar a los otros como instrumentos, como cosas que pueden ser utilizadas (el donante y el hijo son medios para satisfacer el deseo de ser madre) y por tanto implica una amenaza para la convivencia -y para el Derecho en cuanto su garante-, al atacar su fundamentación ontológica, en definitiva, su razón de ser (Ballesteros, 1997, pág. 136). 
Así pues, el amparo y la promoción de la maternidad en solitario por fecundación artificial que regula la normativa española, me ha dado pie para reflexionar de nuevo sobre este aspecto clave de la antropología jurídica, como es la alteridad porque creo que vale la pena recordar el lugar que ocupan en la tarea de encontrar el sentido del Derecho.

\section{Metodología}

\section{El llamado derecho a la maternidad en solitario por fecundación artificial}

\subsection{Aspectos generales}

En España se ha buscado, con la conjugación del avance de las ciencias biomédicas y de una legislación de las más progresistas de nuestro entorno, que la mujer tenga el control de su sexualidad y capacidad reproductiva. El reconocimiento de la capacidad de decisión de la mujer en este contexto ha dado lugar a la creación de nuevos derechos. Surgen así los llamados derechos sexuales $y$ reproductivos que van, a su vez, conectados con el concepto salud sexual y reproductiva ${ }^{8}$. A través de estos nuevos términos se busca otorgar, principalmente a la mujer, la facultad de decidir sin límites sobre su vida sexual y las consecuencias que de ella se derivan (Contreras, 2010) refiere que, de este modo, se pretende que gestione, desde su plena autonomía individual, sus propios proyectos reproductivos (pág. 14). En este contexto se encuadra la posibilidad de que la mujer sin pareja acceda a la

\footnotetext{
${ }^{8}$ Por salud reproductiva se entiende "un estado general de bienestar física o, mental y social, y no de mera ausencia de enfermedades o dolencias, en todos los aspectos relacionados con el sistema reproductivo y sus funciones y procesos". Así aparece definido en el documento resultante de la Conferencia de Población y Desarrollo de las Naciones Unidas que tuvo lugar en 1994 en El Cairo. Doc. de la ONU A/CONF.171/13/Rev.1 (1995).
}

fecundación artificial con cargo a la sanidad pública? .

Esta posibilidad es viable en España desde 1988, primero a través del artículo 6.1 de la derogada Ley 35/1988, de 22 de noviembre, de Técnicas Humana Asistida y hoy día recogida en el artículo 6.1. de la Ley 14/2006, de Reproducción Humana Asistida (Godoy, 2014) refiere que la discusión que desde los primeros momentos se planteó a nivel doctrinal -y vigente hoy día-, pivota en torno a dos cuestiones: si las técnicas de reproducción humana asistida deben o no estar alcance de la mujer sola; y si es conforme a Derecho su promoción por parte de los poderes públicos, planteándose, entre otras dudas, si su fomento pudiera contradecir el interés superior del menor amparado por el orden constitucional (pág. 339).

Por un lado, existe un sector de la doctrina favorable a reconocer el derecho de la mujer a adoptar individualmente sus propias decisiones reproductivas. Son argumentos que se centran, principalmente, en afirmar que el derecho a tener hijos forma parte del derecho al libre desarrollo de la personalidad y del derecho al ejercicio de la libertad personal y sexual (satisfacción del deseo de ser madre) ${ }^{10}$. Esta postura ha sido también defendida en las Conferencias Mundiales por determinados grupos feministas de género, que sostienen "que el fortalecimiento de la mujer descansa en el ejercicio individual de sus derechos, en particular, de sus derechos reproductivos" (United Nations, pág. 45).

\footnotetext{
${ }^{9}$ Si bien, como ya ha sido mencionado, el RD 1013/2006 limitó su acceso. Por otra parte, en la Conferencia Mundial sobre Población y Desarrollo, celebrada en El Cairo (1994) y, posteriormente, en la Conferencia Mundial de la Mujer, celebrada en Pekín (1995), se reconoció de manera expresa la titularidad individual de este derecho. (Organización de la Naciones Unidas, 1994, pág. 41) y (Organización de la naciones unidas, 1995, pág. 45).

${ }^{10}$ Entre otros autores, defienden esta postura en España: (Ocaña Rodríguez, 1993); (Cárcaba, 1995); (López Peláez, 1994). Para un desarrollo exhaustivo y actualizado del régimen jurídico de la tecnología reproductiva en España (Godoy, 2014).
} 
Por tanto, para estas posiciones, el derecho a controlar la propia fecundidad sería la mayor garantía para ejercer con plena libertad los derechos sexuales ${ }^{11}$. Desde este particular punto de vista de la identidad femenina, el derecho a un hijo mediante el libre recurso de las técnicas de reproducción asistida sin cortapisa legal alguna, se reivindica como un derecho reproductivo (Vega, 1998, pág. 19) ${ }^{12}$.

En sentido contrario, otro sector doctrinal ${ }^{13}$ defiende la inexistencia de un derecho subjetivo a la procreación ${ }^{14}$, y considera que el recurso a los gametos donados por terceros en el caso de mujer sola no es un derecho, todo lo más un interés, que en cualquier caso, debería decaer frente al derecho del hijo a tener un doble vínculo filial.

Más recientemente han surgido voces que han alertado de que esta promoción de la maternidad en solitario, al partir de una visión individualista de la sexualidad humana,

\footnotetext{
${ }^{11}$ Hay que matizar que por contro/ entienden la emancipación de su propia sexualidad, de modo que así las mujeres podrían situarse en idéntica posición que los hombres.

12 Como señala E. Fernández, desde esta perspectiva "se produce la asimilación jurídica de las mujeres a los varones. Las mujeres tienen los mismos derechos que los varones porque se finge o se presume que no existen diferencias, en cuanto son consideradas "como" o se finge que son "como" los varones y se asimilan a ellos en los estilos de vida y en los modelos de comportamiento" (Fernández, 2003, pág. 156).La principal consecuencia es que se olvida la diferencia femenina, resultando, por ello, penalizada.

${ }^{13}$ Entre quienes se han mostrado críticos con esta regulación, están (VilaCoro, 1992); (Vidal, Benítez, \& Vega, 1998); (Pantaleón, 1993).

${ }^{14}$ En este sentido, M. D. Vila-Coro razonó, apoyándose en argumentos de A. de la Oliva que, para para discernir si existe no un derecho a procrear hay que plantearse tres cuestiones básicas: titularidad, objeto y contenido. De existir un sujeto debería ser la pareja, nunca la mujer sola, dado que ambos progenitores tendrían el mismo derecho compartido a tener un hijo, y ninguno podría ejercerlo sin el otro. El objeto del derecho a procrear sería tener un hijo, pero el hijo es un ser humano, una persona que por su propia dignidad no puede ser objeto de derecho porque es sujeto de derecho. En este sentido son varios los autores que coinciden en la afirmación de que "ninguna persona puede ser debida a otra como si fuera un bien instrumental" (Vega, Vega, \& Martínez, 1995). En un sentido parecido se pronuncia (Romeo Casabona, 1994). Por último señala Vila-Coro que tampoco hay un contenido definido porque la facultad reproductiva, atendiendo a la pura función biológica, queda fuera de la autonomía de la voluntad en mayor medida que cualquier otro acto fisiológico. No es una consecuencia obligada en toda relación sexual o en todo tratamiento de fecundación artificial. (Vila-Coro, 1992, págs. 3901-3935). Comenta esta argumentación (Godoy, 2014, págs. 340-341).
}

prescindiendo de su dimensión interpersonal, podría conllevar una dejación de responsabilidades por parte del hombre al convertirse sólo en donante de gametos. Situación que no sería compatible con el llamamiento a la corresponsabilidad y a la necesidad de implicar al hombre en las tareas reproductivas -educación, crianza de los hijos, etc.- que se exige desde instancias nacionales ${ }^{15} y$ europeas ${ }^{16}$.

\subsection{El libre juego de la subjetividad}

Como he indicado desde las primeras páginas, el punto de partida para llevar a cabo

\footnotetext{
15 Es diversa la normativa nacional dirigida a fomentar la igualdad de oportunidades entre mujeres y hombres. Entre otras, destacan la Ley 39/1999, de 5 de noviembre, para promover la conciliación de la vida familiar y laboral de las personas trabajadoras; la Ley Orgánica 3/2007, de 22 de marzo, para la igualdad efectiva de mujeres y hombres (cuya Exposición de Motivos establece "el derecho a la conciliación de la vida personal, familiar y laboral y se fomenta una mayor corresponsabilidad entre mujeres y hombres en la asunción de obligaciones familiares, criterios inspiradores de toda norma que encuentran aquí su concreción más significativa"); o el Plan Estratégico de Igualdad de Oportunidades 2014-2016, cuyo eje 2 versa sobre Conciliación de la vida personal, familiar y laboral y corresponsabilidad en la asunción de responsabilidades familiares. (Instituto de la Mujer y para la Igualdad de Oportunidades, 2014 - 2016).

${ }^{16}$ En el marco de la Unión Europea, la Comisión Europea y los interlocutores sociales están promoviendo desde hace años políticas que proporcionen opciones de conciliación entre hombres y mujeres. En este sentido la conciliación de la vida laboral y familiar es un objetivo clave de la nueva estrategia para la igualdad de género 2010-2015 adoptada por la Comisión Europea (European Commission (2010) Gender Equality Strategy, 2010 2015.http://ec.europa.eu/social/main.jsp?langld=en\&catld =89\&newsld =890 \&furtherNews=yes). Es también esencial para cumplir el objetivo de que más mujeres entren en el mercado laboral y para alcanzar el objetivo de la estrategia Europa 2020 de aumentar hasta el 75\% la tasa de empleo de hombres y mujeres. Los interlocutores sociales europeos firmaron un Acuerdo marco revisado sobre el permiso parental en 2009 y aumentaron la duración del permiso parental para todos los trabajadores de tres a cuatro meses por progenitor, con un mes intransferible. Este acuerdo también concede a los progenitores que vuelven al trabajo después del permiso parental, la posibilidad de pedir un cambio en sus horarios laborales y aumenta la protección contra un trato menos favorable o el despido por haber tomado un permiso parental. La conciliación entre la vida laboral y familiar es una de las cuatro áreas prioritarias del Marco de acción para la igualdad de género firmado por los interlocutores sociales europeos (BUSINESS EUROPE, la UEAPME, el CEEP y la CES) en 2005. http://www.ccoo.es/comunes/recursos/1/doc126439 Ficha Informativa Tie mpo de trabajo, Iqualdad de genero $y$ conciliacion de la vida familiar $y$ laboral..pdf. En este documento se pueden encontrar también distintas propuestas legislativas de varios países de la Unión Europea enfocadas a la corresponsabilidad familiar. Por otro lado, en mayo de 2011, cinco años después del primer Pacto Europeo por la Igualdad de Género de 2006, el Consejo de la Unión Europea, consciente de la necesidad de reafirmar y apoyar la estrecha relación entre la Estrategia de la Comisión Europea para la igualdad entre mujeres y hombres (2010-2015) y la Estrategia Europa 2020, reafirmó su voluntad de cumplir con los objetivos de la UE en materia de igualdad entre mujeres y hombres y adoptó un segundo Pacto Europeo por la Igualdad de Género (2011-2020).
} 
esta reflexión es que la alteridad es una nota inherente al Derecho. Hablar de Derecho y alteridad implica poner el acento en que el Derecho no es una realidad ceñida a un sujeto sino que requiere como mínimo dos sujetos distintos: el titular del derecho lo tiene frente a otro u otros sujetos, los cuales deben obrar en justicia respecto al titular (Hervada, 1992, pág. 228 $)^{17}$. Hablar de alteridad, por tanto, denota la condición de ser en relación con otro. El Derecho surge en el seno de una relación entre dos o más personas, dicho de otro modo, la relacionabilidad interpersonal está en la raíz antropológica de lo jurídico.

A sensu contrario, la simple atribución de la cosa al sujeto, abstracción hecha del deber de los demás de no interferencia, no genera el derecho. Así, el solitario incomunicado posee cosas y las domina, pero estas relaciones no son jurídicas hasta que no participa otro $u$ otros sujetos (Basave, 1980, pág. p. 233). El Derecho implica "pluralidad de términos conectados, acoplamiento de igualdades, supuestos diferentes que entrañan, ineludiblemente, la alteridad. De hecho, no hay derecho consigo mismo -salvo que se quiera hablar en sentido metafórico-. Todo ello encarnado en personas humanas comunicantes, actuantes y responsables" (Basave, 1980, págs. 232-233). Por tanto, la vida social desarrollada conforme a al Derecho, no puede consistir en actividades egoístas centradas en el uso y reivindicación de derechos subjetivos ${ }^{18}$; debe ser una vida social abierta a los demás, que mira a que cada uno tenga lo suyo -lo que le corresponde- y esté en el legítimo uso y disfrute de su derecho. La actividad jurídica representa la más básica dimensión de solidaridad entre los seres humanos (Hervada, 1992, pág. 248). Desde este punto de vista, el Derecho es lo opuesto a

\footnotetext{
${ }^{17}$ Por tanto, la alteridad en el Derecho implica un deber ante el derecho del otro.

18 "La obligación de los poderes públicos de velar por el bienestar del futuro hijo incluye la obligación de velar porque el hijo no tenga la consideración de objeto de un derecho subjetivo". (Romeo Casabona, 1994, pág. 237).
}

potenciar unilateralmente el yo (el ego): frente al egoísmo, alteridad.

Así pues, siguiendo este hilo argumental y volviendo al caso que nos ocupa, en mi opinión, no es propio de la actividad jurídica el amparo de comportamientos individualistas, centrados en el uso y reivindicación de derechos subjetivos, como sucede en el supuesto comentado. Todo lo contrario, según vengo afirmando, la actividad jurídica debe proteger una vida social abierta a los demás, que vele porque cada uno tenga lo suyo sin que nadie quede desprotegido (Hervada , 1992). Pero para que se de esta dimensión de solidaridad es necesario, como ya Aristóteles intuyó, reconocer al otro como un alter ego. La dimensión de reciprocidad, de respeto mutuo es un elemento fundamental para la existencia del Derecho. La idea del respeto universal al otro sin discriminación va a ser uno de los factores fundamentales en la toma de conciencia del sentido genuino de lo jurídico ${ }^{19}$. Si no reconozco al otro como otro yo, lo que prevalece por el contrario es el narcisismo individual, que se caracteriza por fundar la relación de alteridad en el deseo de uso, dominación o goce (Ballesteros, 1997, pág. 127).

Precisamente, frente a la voluntad aleatoria, Ballesteros muestra como incluso a través de la etimología, el Derecho implica la dimensión de compromiso y de fidelidad ${ }^{20}$. El mismo concepto de Derecho habla de rectitud y fidelidad, de constancia. Esta dimensión de la constancia, de la permanencia de la voluntad está presente en la experiencia jurídica desde la Antigüedad, así lo prueba el énfasis en la dimensión de la fides, "constancia y verdad en el empleo de la palabra por parte de los que

\footnotetext{
${ }^{19}$ Afirma Ballesteros: "No en balde la humanitas negada en toda época de barbarie junto con la fides, el pudor y la pietas, va a ser reclamada como exigencia básica para todo buen jurista". (Ballesteros, 1997, págs. 97-98).

20 "En todo caso, parece además claramente probado que ius no deriva de iubeo y iussum, como se habría pretendido en ocasiones, sino más bien de iuro, iurare, que guarda a su vez relación con el sanscrito $y u$, que implica la dimensión de rectitud y fidelidad, de origen sagrado". (Ballesteros, 1997, págs. 91, 95-96).
} 
contratan", como base de la justicia, tal y como pone de relieve Cicerón, así como la definición de justicia propuesta por Ulpiano: "voluntad constante y perpetua de dar a cada cual lo suyo". En el supuesto que se analiza, el marco de apoyo lo da el deseo de ser madre, pero según venimos afirmando, el Derecho viene a establecer la fidelidad de las acciones humanas en cuanto que son relevantes para otros. Por eso la importancia de la promesa como fundamento de gran parte de las instituciones jurídicas. De ahí se desprende la incomprensión ante el Derecho de situaciones que vienen a responder al instante presente, porque de este modo el Derecho se convierte en expresión de pretendidos derechos a la satisfacción de los deseos e impulsos humanos; de este modo, los otros son vistos como simples instrumentos, simples cosas que pueden ser utilizadas (el donante, el hijo) con lo que convivencia queda amenazada en su misma fundamentación ontológica (Ballesteros, 1997, págs. 131-136). Frente al instanteneísmo, el Derecho es compromiso.

Como indicaba al inicio de estas páginas, el supuesto de fecundación de mujer sola tal y como lo regula la legislación española, destaca por su espíritu individualista. El único objetivo de la norma es garantizar y promocionar el derecho de la mujer a procrear. De este modo, se prima la libertad de elección y configuración de la propia vida en detrimento de, por un lado, los derechos del hijo (a quien, entre otras consecuencias, se le niega conocer la identidad de su progenitor y queda privado de crecer y desarrollarse en una familia biparental); $y$, por otro lado, del fomento de un modelo de corresponsabilidad de ambas partes de la relación.

Efectivamente, las repercusiones de la maternidad en solitario que promociona la Ley recaen de manera directa sobre el hijo o la hija, $y$, a mi juicio, coincido con quienes afirman que la solución legal adoptada lesiona su dignidad al negarle el ejercicio del derecho fundamental a conocer su propio origen ${ }^{21}$; y anula el espíritu del artículo 39 de la Constitución, que impone a los poderes públicos la obligación de velar y garantizar la protección integral de los hijos y de la familia ${ }^{22}$.

Por último, la defensa que nuestro ordenamiento interno hace de la titularidad individual de este supuesto derecho reproductivo-siendo el titular exclusivamente la mujer- a mi juicio no casa bien con el modelo que está siendo impulsado por las políticas de conciliación que se están elaborando desde España y desde la Unión Europea. Políticas que hacen hincapié en que la cuestión de la natalidad y las tareas reproductivas no son sólo algo que compete a las mujeres, sino que existe un interés social en apoyar la educación y crianza de los hijos como tarea de corresponsabilidad entre los dos progenitores, en cuanto que se afirma que también es cosa de hombres (Elosegui, 2002) ${ }^{23}$.

\section{Conclusiones}

\section{Valoraciones finales}

Me proponía, al comenzar este trabajo, reflexionar sobre la alteridad como un elemento que está situado en la raíz de la antropología jurídica. Para ello, tomé como referencia el

\footnotetext{
${ }^{21}$ Derecho garantizado para el supuesto de adopciones a través del artículo 5 de la Ley 54/2007, de 28 de diciembre, de Adopción Internacional.

${ }^{22}$ A lo que podría añadirse la duda de que el Estado tenga la obligación de proporcionar el suministro de gametos con cargo a la sanidad pública (especialmente cuando la mujer no se encuentra "aquejada", si se permite el término, de esterilidad). (Godoy, 2014, pág. 344).

${ }^{23}$ Según consta en el Plan Estratégico de Igualdad de Oportunidades 2014 2016, "es necesario impulsar medidas en apoyo de la conciliación de la vida personal, familiar y laboral tanto de mujeres como de hombres, así como un mayor equilibrio en la asunción de responsabilidades por parte de ambos, tanto en beneficio de las familias, como para alcanzar la igualdad real de oportunidades entre mujeres y hombres" (Instituto de la Mujer y para la lgualdad de Oportunidades, 2014 - 2016).
} 
análisis de la promoción de la maternidad en solitario que hace nuestra legislación. Pues bien, una vez expuestos los argumentos, querría resaltar a modo de valoraciones finales, algunos aspectos que me parecen dignos de mencionar.

En primer lugar, como es sabido, el Derecho tiene un papel estelar en la estructura fundamental de la sociedad, siendo una herramienta para la mejor coexistencia. En las obras de los juristas clásicos se le reconoce al Derecho la función de conseguir no solo ciudadanos sino buenos ciudadanos ${ }^{24}$.

Para que el Derecho pueda desempeñar esta labor es imprescindible el reconocimiento de la paridad ontológica entre los seres humanos: sólo a través del reconocimiento del alter ego el ser humano afirma su racionalidad en la reciprocidad del reconocimiento (Romano , 1997). Por tanto, consolidar como derecho un interés individual, por muy legítimo que éste que pueda ser, prescindiendo de los derechos de los terceros implicados o, cuanto menos, restringiéndoles sus derechos, no responde al genio del Derecho. A mi juicio, el derecho específico a recurrir a gametos anónimos para procrear en solitario presenta una base jurídica muy cuestionable. Pienso que es necesaria la adopción de un nuevo enfoque en esta materia, que tenga presente que los seres humanos somos seres en relación, no somos simples vivientes sino que somos convivientes. No olvidemos que con la alteridad, al referirla al Derecho, se pone la nota en la relación personal, entre yo (mi ego) y el otro (mi alter ego).

Por otra parte, según he venido argumentando, que el Derecho ordene la vida social implica que su actividad no puede ser individualista ni egoísta, centrada en el uso y reivindicación de intereses individuales. Todo lo

${ }^{24}$ Aristóteles (Ética a Nicómaco, V, 1), Ulpiano (Digesto1.1.10.1) o Santo Tomás, (Summa Theologica, I-II, Q. 92) contrario, debe ser una actividad abierta a los demás. Así contemplada, la actividad jurídica representa la más básica dimensión de solidaridad entre las personas, por eso la vida social ordenada por el Derecho conserva y refuerza la comunidad. Si el Derecho prescinde de la nota de alteridad, si se convierte en un medio al servicio de los intereses individuales, queda desvalorizado, desontologizado. La exaltación de los deseos conduce, inevitablemente, a la pérdida del sentido del Derecho como respeto universal al otro, como puede verse en el trato al donante y al hijo como medios para alcanzar un fin $^{25}$. Por tanto, las exigencias que van íntimamente unidas a la dimensión del Derecho, como el compromiso, la solidaridad, la humanitas, la exigencia del respeto al otro, son desvalorizadas (Ballesteros, 1997, pág. 36). En definitiva, olvidar la nota de alteridad -primar el ego en detrimento del alter ego-, no solo pone en juego el sentido del Derecho sino el sentido mismo del ser humano.

\section{Bibliografía}

Ballesteros, J. (1997). Sobre el sentido del Derecho: Introducción a la Filosofía Jurídica (Vol. II). Madrid: Tecnos.

Basave, A. (1980). Hacia una antropología jurídica integral. Persona y Derecho.

Cárcaba, M. (1995). Los problemas jurídicos planteados por las técnicas de reproducción humana. Barcelona: Bosch.

Contreras, F. J. (2010). La ideología de los derechos reproductivos. Jaén: ANDOC.

Elosegui, M. (2002). Diez temas de género. Hombre y mujer ante los derechos productivos $y$ reproductivos. Madrid: EUNSA.

\footnotetext{
${ }^{25}$ Sin entrar en cuestiones que exigirían un trato más detallado, sí que creo que es importante distinguir dos situaciones muy distintas pero que pudieran confundirse como son la adopción y el supuesto de inseminación de mujer sola. Desde un punto de vista jurídico la diferencia es evidente: la adopción busca proteger el mayor interés del menor que ya existe, el segundo supuesto busca satisfacer el deseo de ser madre.
} 
Fernández, E. (2003). Igualdad y Derechos Humanos, Madrid. Tecnos.

Godoy, M. O. (2014). Régimen jurídico de la tecnología reproductiva y la investigación biomédica con material humano embrionario. Madrid: Dykinson.

Hervada , J. (1992). Lecciones propedéuticas de Filosofía del Derecho. Pamplona: EUNSA.

Instituto de la Mujer y para la Igualdad de Oportunidades. (2014 - 2016). Plan Estratégico de lgualdad de Oportunidades. (I. d. Oportunidades, Ed.) Obtenido de http://www.inmujer.gob.es/actualidad/PEIO/d ocs/PEIO2014-2016.pdf

López Peláez, P. (1994). Relaciones civiles derivadas de la fecundación post-mortem. Boletín de la Facultad de Derecho de la UNED, 109-141.

Ocaña Rodríguez, A. (1993). La filiación en España. Granada: Comares.

Organización de la Naciones Unidas. (1994). ICPD, A/CONF. 171/13.

Organización de la naciones unidas. (1995). Conferencia mundial de la Mujer. A/CONF. 177/20. Pekín.

Pantaleón, F. (1993). Técnicas de reproducción asistida y Constitución. Revista del Centro de Estudios Constitucionales, 129-160.
Romano , A. (1997). Derecho y racionalidad intersubjetiva. Persona y Derecho, 277-278.

Romeo Casabona, C. M. (1994). El Derecho y la Bioética ante los límites de la vida humana. Madrid: Centro de Estudios Ramón Areces.

San Julián, V., \& Díaz de terán, M. C. (2013). Corps de la femme et Biomédicine. Approche internationale.

Vega, A. M. (1998). Derechos reproductivos y técnicas de reproducción asistida. Granada: Comares.

Vega, A., Vega, J., \& Martínez, P. (1995). El hijo en la procreación artificial. Implicaciones éticas y médico-legales. Cuadernos de Bioética, 56.

Vidal, J., Benítez, J. I., \& Vega, A. M. (1998). Derechos reproductivos y técnicas de reproducción asistida. Granada: Comares.

Vila-Coro, M. D. (1992). La reproducción asistida en la mujer sola. Revista General del Derecho, 3901-3935. 